\title{
Quinoxaline as a potent heterocyclic moiety
}

\author{
Sujiti Srivastava, ${ }^{1}$ Janmajoy Banerjee* ${ }^{1}$ Nomi Srestha ${ }^{1}$ \\ Department of pharmacy, Sunsari Technical College, Dharan NEPAL
}

\begin{abstract}
Various novel, mild, eco-friendly and efficient methods has been developed for the preparation of quinoxaline derivatives in high yields via condensation of aromatic diamine and 1,2-dicarbonyl compounds or alphahydroxyketones in the presence of different catalyst such as CuSO4/KMno4, iodine, phenol similarly by using different solvents such as water, ethanol. As part of current studies, we here in report efficient practical techniques like- sonication (sonochemistry sythesis), heating, grinding and simple mortal-pastel methods (mechanochemistry). However, all results suggest a mild and heterogeneous nature of these mechanisms, shorter time of reaction and higher yield or similar to reported older methods, the review here is to highlight some convenient methods of synthesis with keeping an eye to their various biological importances.
\end{abstract}

KEYWORDS-alphahydroxyketones, sonochemistry, antioxidantactivity.

Methods for synthesis of quinoxaline:

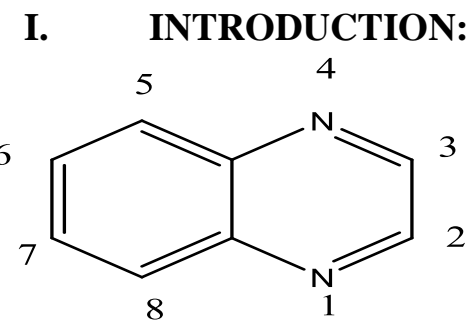

Fig: Structure of quinoxaline

The current review mainly concern with the catalytic method of synthesis of quinoxaline derivatives. Due to the important role in lead optimization as well as for the synthesis of derivatives, effective and convenient methods are a serious need for medicinal chemistry.Quinoxaline is commonly called as or benzopyrine. . Quinoxaline and its derivatives are mostly of synthetic origin. The fusion of one or two benzene rings in quinoxaline and phenazine increases the number of resonance structure, which are available to these systems. It posses the dipole moment of zero. Considering these properties, various research workers have shown a keen interest in this small heterocyclic moiety as target structure for evaluation of many pharmacological activities. This review includes various synthetic routes and guidelines for the development of new quinoxalines

Nitrogen containing heterocyclic compounds are indispensable structural units for both the chemists and biochemists.Among the various classes of benzene fused six-membered nitrogen containing heterocyclic compounds,quinoxaline derivatives form an important class of pharmacologically active compounds. The numbering and chemical sturucture is as shown above. Numerous quinoxaline derivatives have important biological activity such as antibacterial[1], , anticancer[2], anti-inflammatory agents[3] antimycobial and anticandida[4], cytotoxic[5], Antioxidant[6], Anticonvulsant[7], antiviral[8], SR protein-specific kinase-1 inhibitor[9] activity.

\section{CHEMISTRY}

Quinoxaline is a low melting solid, m.p $29-30^{\circ} \mathrm{C}$ and is miscible with water. It is weakly basic pKa 0.56. Quinoxaline forms salts with acids. Nitration occurs only under forcing conditions (Conc. HNO3, Oleum, $90{ }^{\circ} \mathrm{C}$ ) to give 5-nitroquinoxaline (1.5\%) and 5, 7-dinitro- quinoxaline (24\%).

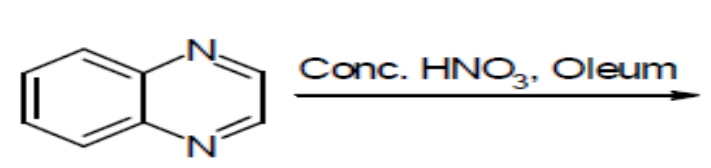<smiles>O=[N+]([O-])c1cccc2nccnc12</smiles>

$1.5 \%$<smiles>O=[N+]([O-])c1cc([N+](=O)[O-])c2nccnc2c1</smiles>

$24 \%$ 
Oxidation of quinoxaline results in the formation of the product depending on the nature of the oxidizing agent employed. With alkaline potassium permanganate pyrazine 2,3-dicarboxylic acid is formed, while with peracid quinoxaline di-N-oxide results.[10]

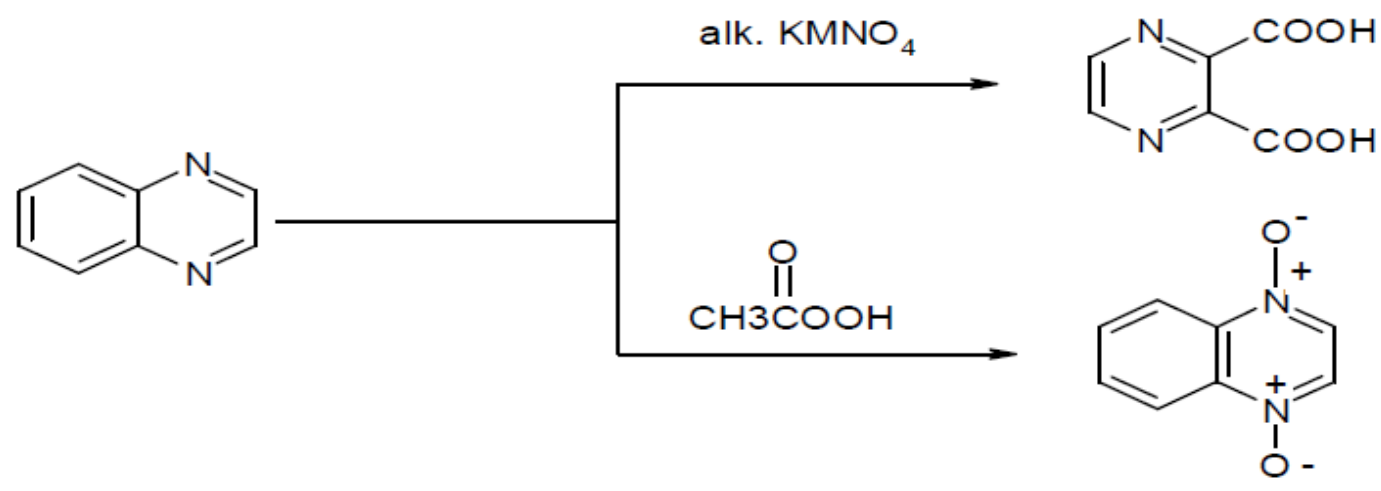

\section{SYNTHESIS:}

1. Atghia and Beigbaghlou examined the reaction of 1,2-phenylenediamine $(1 \mathrm{mmol})$ with benzil $(1 \mathrm{mmol})$ in various solvents (EtOH, THF, MeCN, EtOAc, and toluene) and also under solvent-free classical heating conditions in the presence of different amounts of the catalyst. The best result was achieved by carrying out the reaction in the presence of $10 \mathrm{mg}$ of $\mathrm{TiO} 2-\mathrm{Pr}-\mathrm{SO} 3 \mathrm{H}$ in $\mathrm{EtOH}[11]$<smiles>[X]c1ccc(N)c(N)c1</smiles>

$\mathrm{X}=\mathrm{H}, \mathrm{NO}_{2}$<smiles>[X]c1ccc2nc([R])c([R])nc2c1</smiles>

$\mathrm{X}=\mathrm{H}, \mathrm{NO}_{2}$

2. Sajjadifar developed a novel, mild, eco-friendly and efficient method for the preparation of quinoxaline derivatives in high yields via a one-pot condensation of aromatic diamine and 1,2-dicarbonyl compounds in the presence of [2-(sulfooxy)ethyl]sulfamic acid (SESA)[12].<smiles>NC1=[X]#[R]=CC=C1N</smiles><smiles>O=C(c1ccccc1)c1ccccc1</smiles>

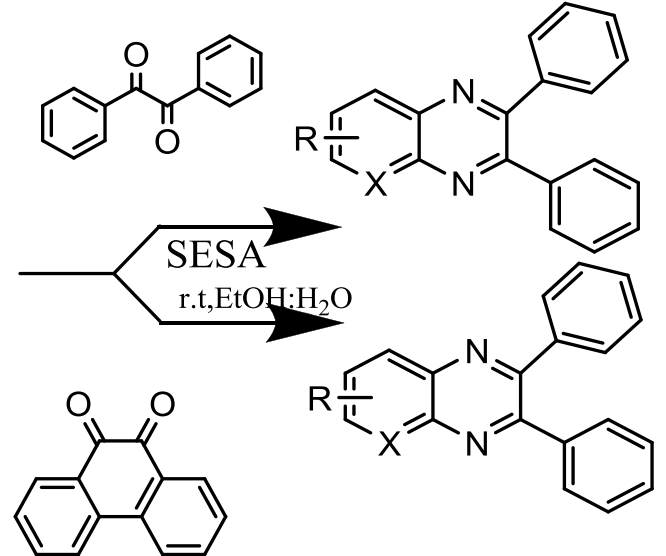

\section{$\mathrm{X}=\mathrm{CH}, \mathrm{N}$}

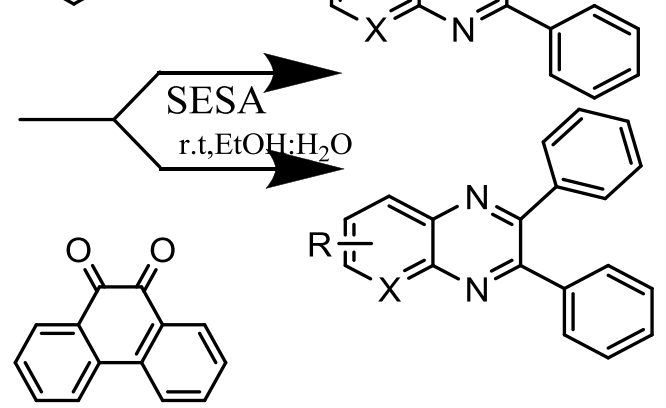

3. Karami And Khodabakhshi produced a Convenient and simple procedures for the synthesis of phenazine and quinoxaline derivatives were developed via a reaction of o-phenylenediamines and 1,2-dicarbonyl compounds. In addition, the synthesis of two new 1,4-benzodiazine derivatives and the catalytic activity of magnesium sulfate heptahydrate $\left(\mathrm{MgSO}_{4} \cdot 7 \mathrm{H}_{2} \mathrm{O}\right)$ in the room temperature condensation of o-phenylenediamines and 1,2dicarbonyl compounds in ethanol as solvent are reported[13]. 


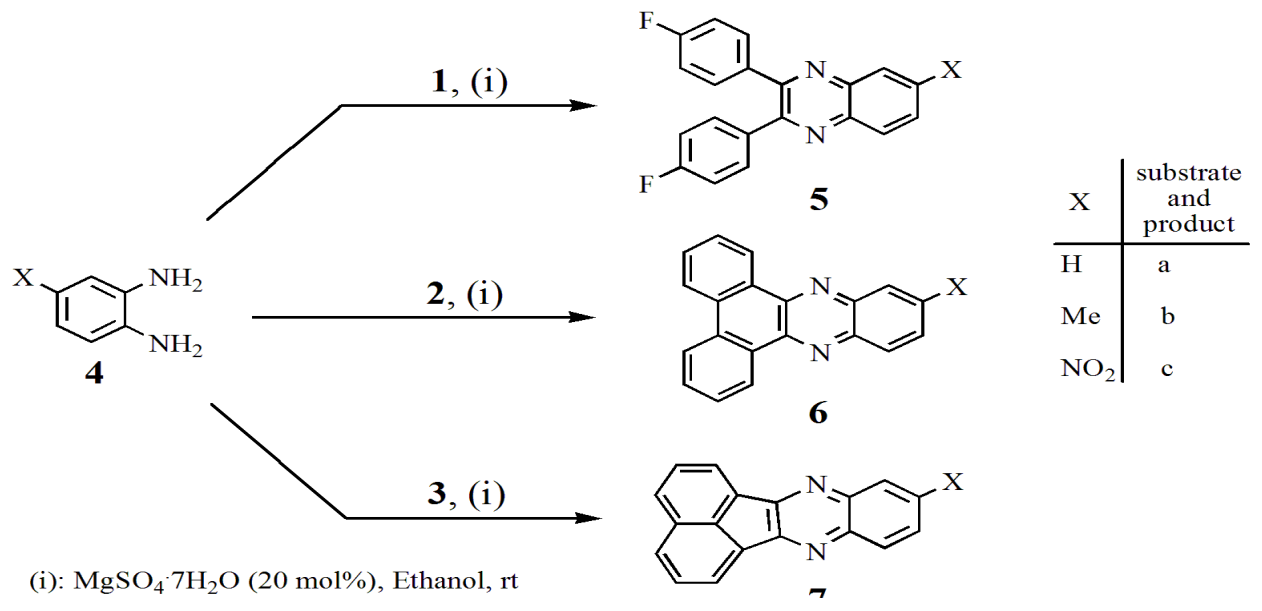

4. Heravi et al o-Iodoxybenzoic acid (IBX), a readily available hypervalent iodine (V) reagent, was found to be highly effective in synthesis of quinoxaline derivatives, from 1,2-diketones and ophenylenediamines at room temperature in very high yields[14]<smiles>[R]c1ccc(C(=O)C(=O)c2ccc([R])cc2)cc1</smiles>

2<smiles>[R]c1ccc(-c2nc3ccc([R1])cc3nc2-c2ccc([R])cc2)cc1</smiles>

3

5. Fan and Hua studied, $\mathrm{Yb}$ immobilized $\mathrm{NaY}$ zeolite catalyst ( $\mathrm{Yb} / \mathrm{NaY}$ ) which was obtained by a hydrothermal method and characterized by XRD, BET, FT-IR, ICP-AES, and NH3-TPD. The catalyst displayed good catalytic activity when applied to the synthesis of quinoxalines via condensation of a-hydroxyketones with 1,2diamines, and could be reused several times without any loss of catalytic activity[15].

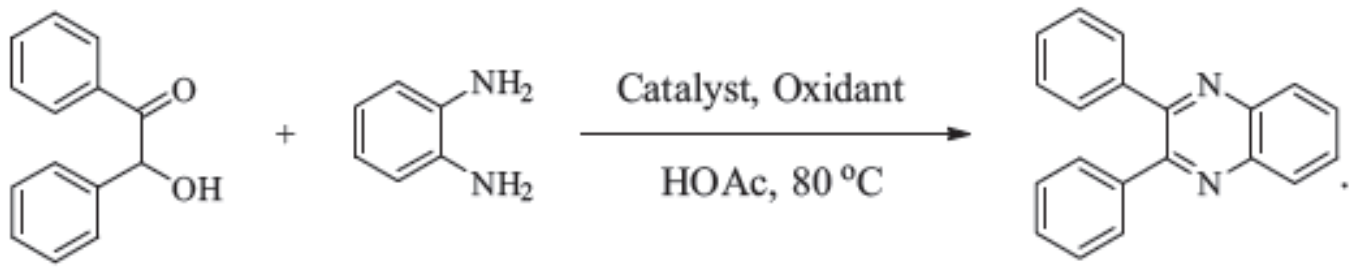

6. Nagarapu and et al synthesized Quinoxaline derivatives by a simple, efficient, one-pot, two-component condensation of $\alpha, \beta$-unsaturated ketones, o-phenylenediamine in the presence of a catalytic amount of $5 \%$ $\mathrm{WO} 3 / \mathrm{ZrO} 2$ in excellent yields. The effect of electron releasing and electron with drawing substituent on the aromatic ring of phenacyl bromides on the reaction was investigated. Electron releasing groups and electron withdrawing groups did not affect significantly on the yields and the reaction times. Using 1,2-diamines possessing electron-withdrawing substituent needed longer reaction times and the yields were lower[16].<smiles>Nc1ccccc1N</smiles>

1<smiles>[H][R]1cccc(C(=O)CBr)c1</smiles>

2

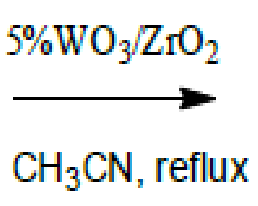<smiles>[Tl]c1nc2ccccc2nc1-c1cc[R]cc1</smiles>

3a-k 
7. Soleymani et al synthesized compounds based on condensation of Aryl-1,2-di amine with 1,2-di carbonyl in the acidic condition, some new compounds was obtained from Quinoxaline family that for the first time some new catalysts was used for increasing of efficiency and reducing of process time. Used catalysts were $\mathrm{CrCl} 2.6 \mathrm{H} 2 \mathrm{O}, \mathrm{PbBr} 2$ and $\mathrm{CuSO} 4.5 \mathrm{H} 2 \mathrm{O}$ compounds that preparation of these catalysts is economically, costeffective and saves time. All mechanisms were done in ethanol solvent at room temperature[17]
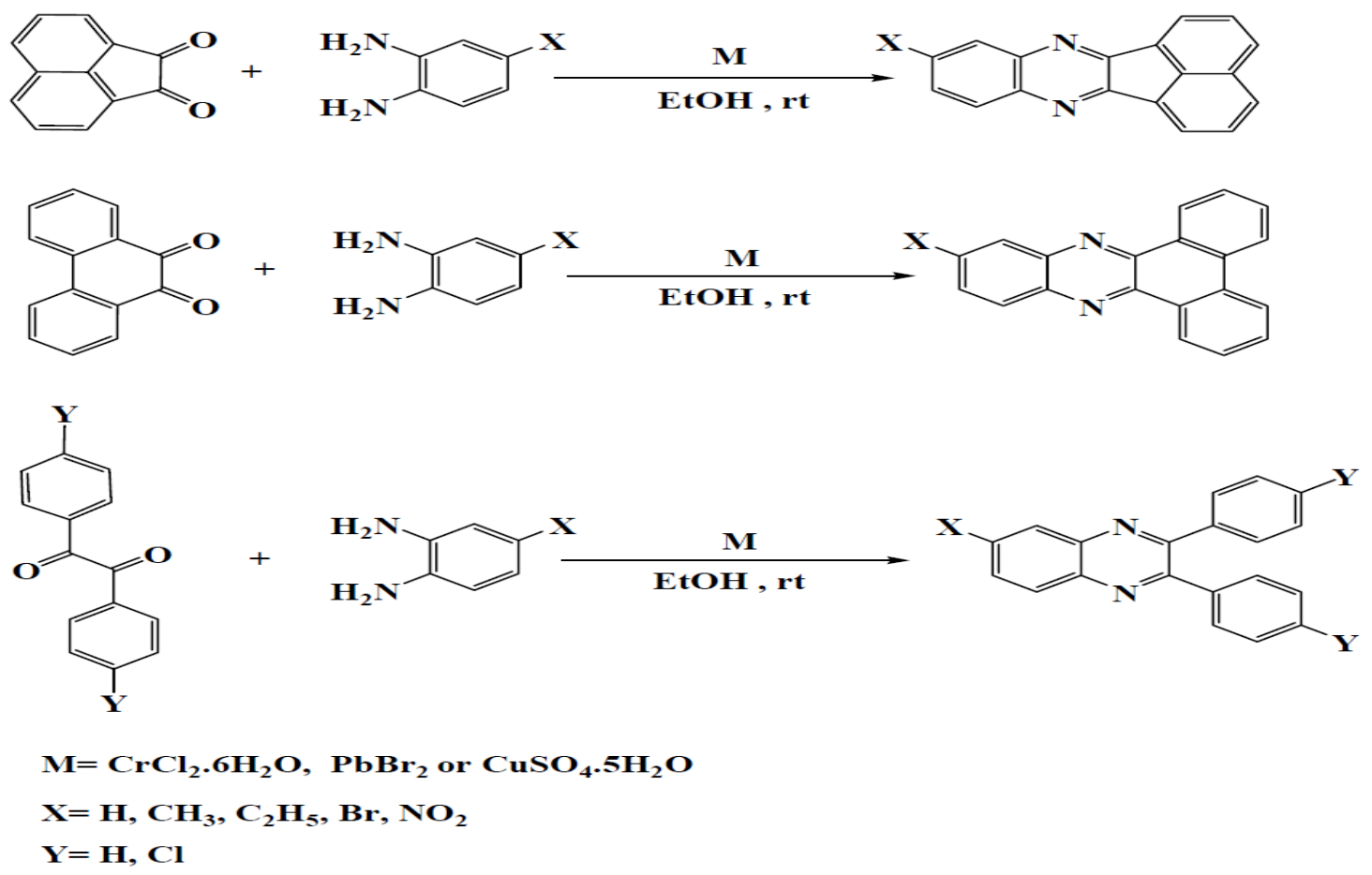

8. Sajjadifar et al described a simple, highly efficient and green procedure for the condensation of aryl and alkyl 1,2-diamines with $\alpha$-diketones in the presence of catalytic amount of citric acid at room temperature . Using this method, quinoxaline derivatives as biologically interesting compounds are produced in high to excellent yields and short reaction times under mild and green condition. In this research, new quinoxaline derivatives were produced.[18]
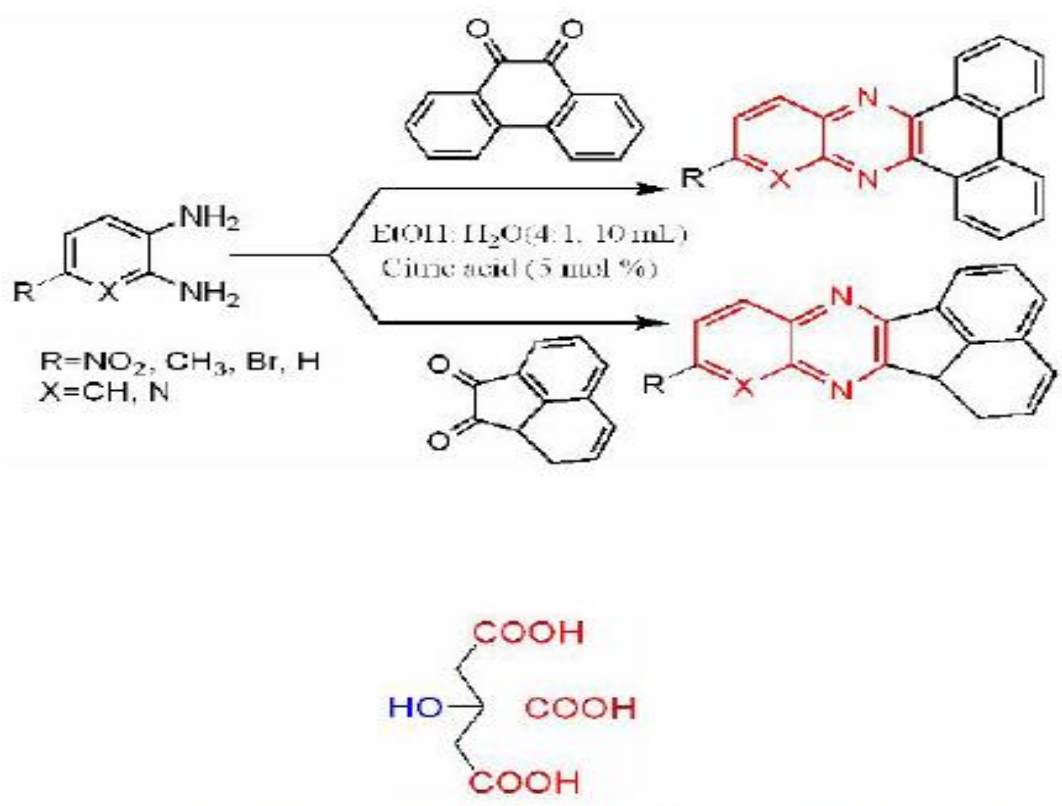

Figure 1- Citric acid structure as a trifunctional Bronsted acid 
9. Biswas et al developed an operationally simple and efficient cascade strategy to access substituted isoindolo[2,1-a]quinoxalines via one step copper-catalysed C-N coupling of substituted 2H-isoindole-1carbaldehyde and substituted 2-halophenylamines . Another straight forward procedure to prepare substituted isoindolo[2,1-a]quinoxalin-6(5H)-ones involving transformation of substituted $2 \mathrm{H}$-isoindole-1-carboxylic acids to acid chloride, coupling with substituted 2-iodophenylamines and copper-catalysed $\mathrm{C}-\mathrm{N}$ coupling is described[19]
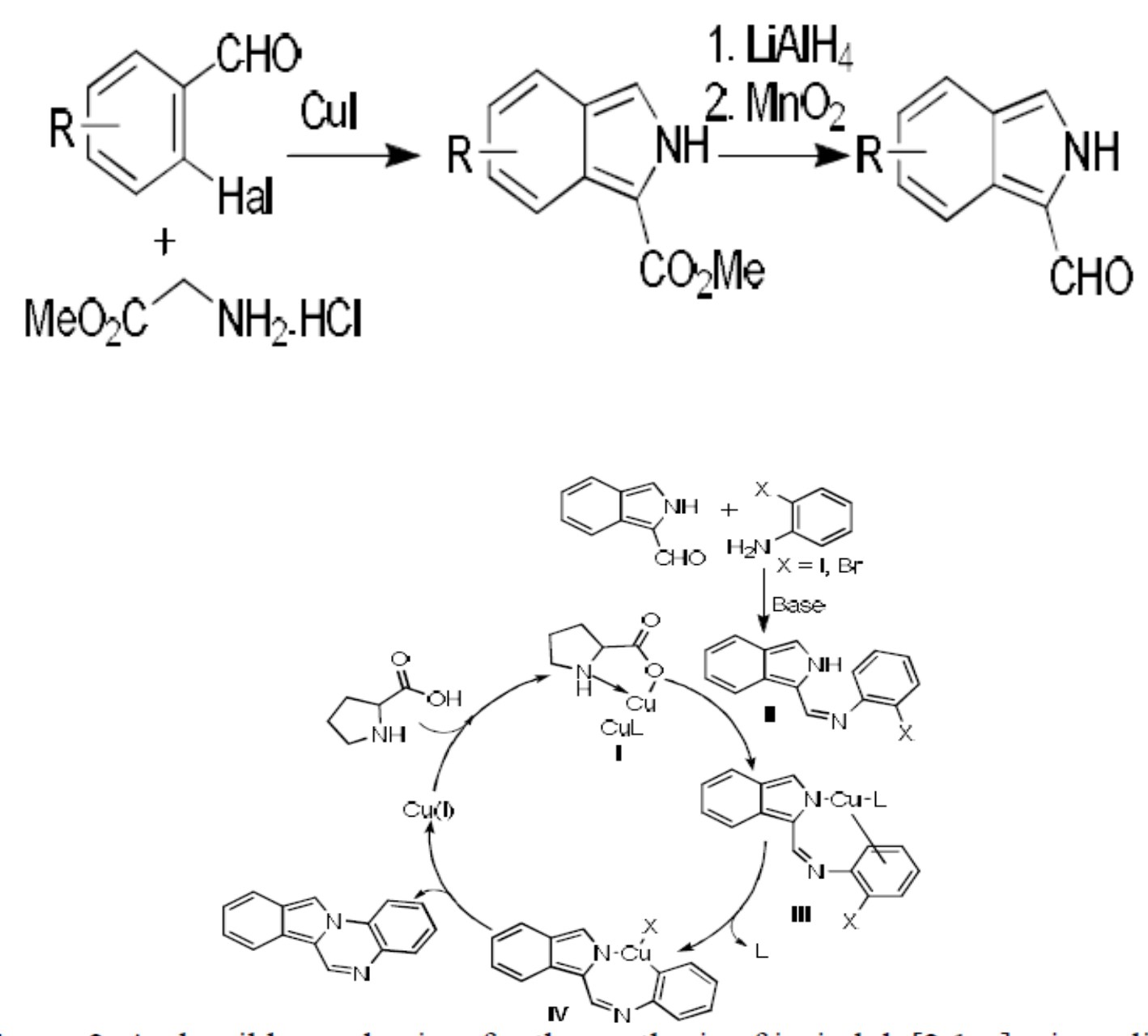

Scheme 2. A plausible mechanism for the synthesis of isoindolo $[2,1-a]$ quinoxaline

10.Shi et al described an efficient and clean method for the synthesis of 1,5-benzodiazepines from ophenylenediamine and ketones catalyzed by sodium tetrachloroaurate(III) dihydrate under mild conditions. The catalyst was shown to be equally effective for the synthesis of quinoxalines from o-phenylenediamine and $\alpha$ bromo ketones under the similar reaction conditions. This method produced good yields[20].

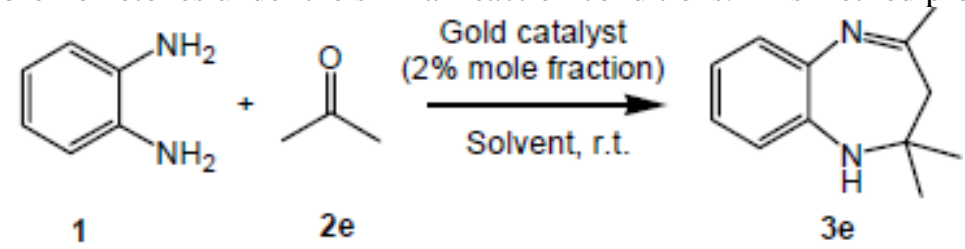

11. Yun-fei et al described $\mathrm{Ga}(\mathrm{ClO} 4) 3$-catalyzed reaction of 1,2-aryldiamines and $\alpha$-bromoketones to afford 2substituted quinoxalinesbin good yields. The reaction proceeded via grinding process with $10 \%$ (molar fraction) catalyst underbsolvent-free conditions at room temperature[21]

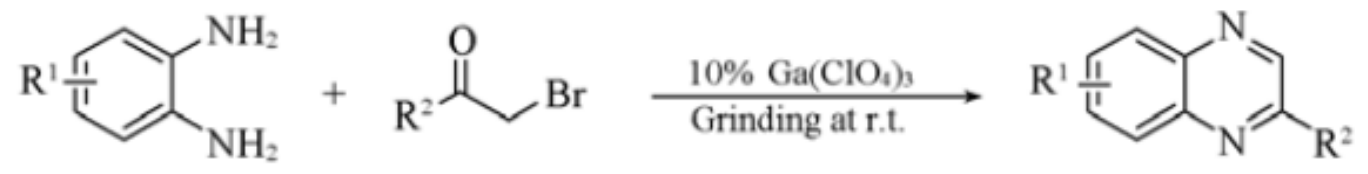




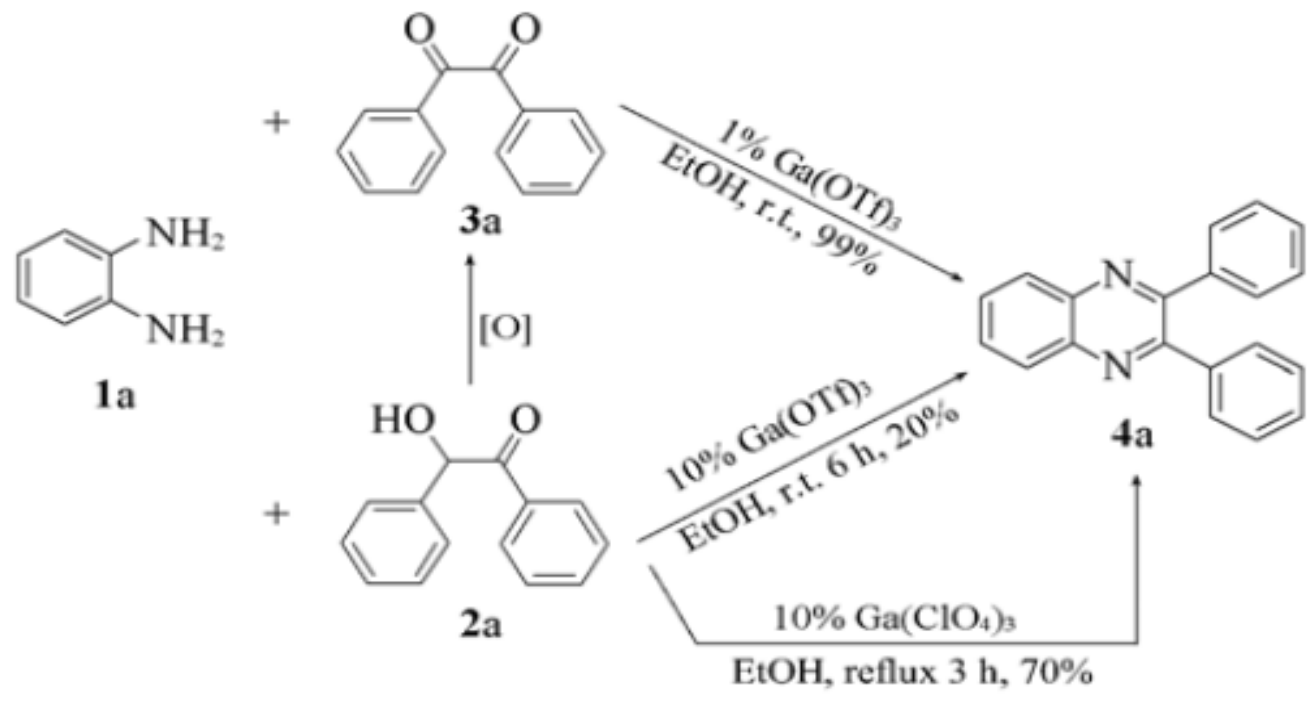

11. Huang et al found Keggin type heteropolyacids to be an efficient and reusable catalyst for the synthesis of biologically active quinoxaline derivatives from the condensation of 1,2-diamine with 1,2-dicarbonyl compounds in excellent yields in water. This method provides a new and efficient protocol in terms of small quantity of catalyst, a wide scope of substrates, and simple work-up procedure[22].

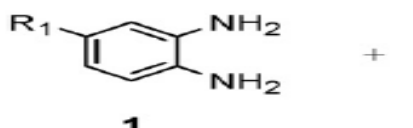<smiles></smiles>

2

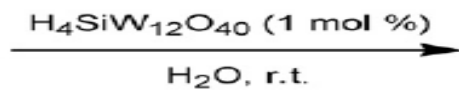

$\mathrm{H}_{2} \mathrm{O}$, r.t

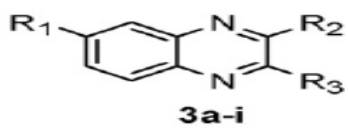

12. Cartigny et al developed a highly efficient and general iridium-difluorphos-catalyzed asymmetric hydrogenation of diverse 2-alkyl- and 2-aryl-substituted quinoxalines into biologically and pharmaceutically relevant 2-substituted-1,2,3,4-tetrahydroquinoxaline units has been developed. High isolated yields and excellent enantioselectivities of up to $95 \%$ for 2-alkyl-substitutedquinoxalines and of up to $94 \%$ for 2 -arylsubstituted quinoxalines were obtained.[23]

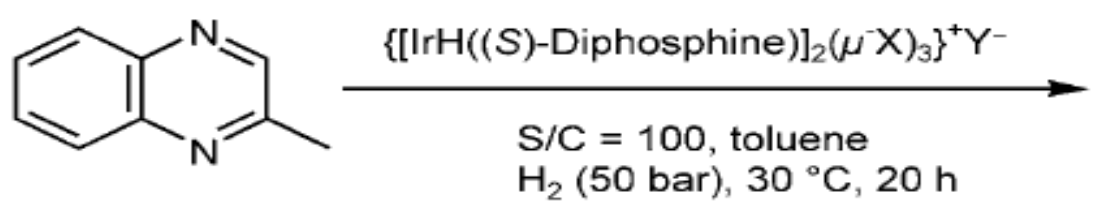<smiles>C[C@@H]1CNc2ccccc2N1</smiles>

13. Pawar et al synthesized quinoxaline derivatives in high to excellent yields in the presence of thiamine hydrochloride (VB1) as an inexpensive, nontoxic and metal ion free catalyst at ambient temperature.[24]<smiles>[R]c1ccc(C(=O)C(=O)c2ccc([R1])cc2)cc1</smiles>

14. Heravi et al found o-Iodoxybenzoic acid (IBX), a readily available hypervalent iodine (V) reagent, to be highly effective in synthesis of quinoxaline derivatives, from 1,2-diketones and ophenylenediamines at room temperature in very high yields.[25] 


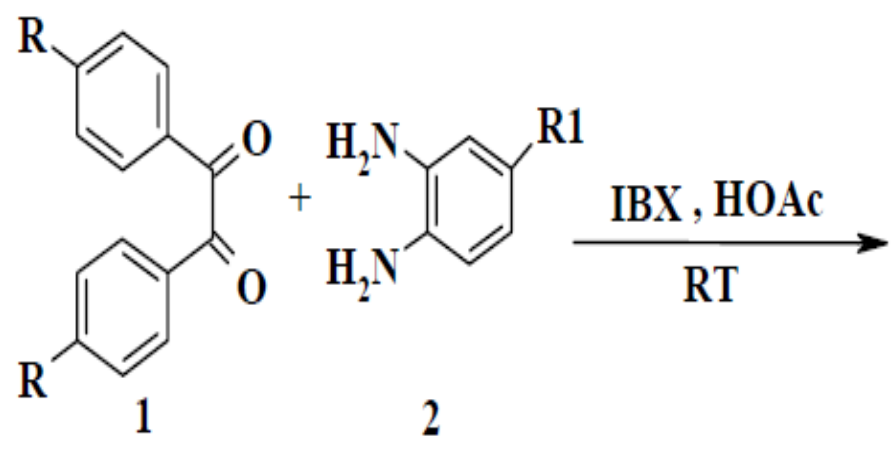<smiles></smiles>

15. Bandyopadhyay et al produced a microwave-induced iodine-catalyzed simple, rapid and convenient synthesis of different types of quinoxalines via condensation of 1,2-diamines with 1,2-dicarbonyl compounds.[26]<smiles>[R]c1ccc(N)c(N)c1</smiles>

$$
\begin{aligned}
& \mathrm{R}_{1}=\mathrm{H}, \mathrm{Cl}, \mathrm{OMe}, \mathrm{NO}_{2} \\
& \mathrm{R}_{2}=\mathrm{H}, \mathrm{CH}_{3}, \mathrm{Ph}
\end{aligned}
$$

16.Das and Sarkar carried out an efficient environmentally benign condensation of 1,2 diketones and 1,2diamines for a facile synthesis of quinoxalines was carried in aqueous medium in the presence of tetraethylammonium bromate. [27]<smiles>[R]C(=O)C([R])=O</smiles>

$$
\begin{aligned}
& \mathrm{R}=\mathrm{H}, \mathrm{Cl}, \mathrm{Me} \\
& \mathrm{R}_{1}=\mathrm{Ph}, 4-\mathrm{MePh}, 2 \text {-furyl }
\end{aligned}
$$

PHARMACOLOGICAL ACTIVITIES

\begin{tabular}{|l|l|l|l|l|}
\hline S.NO. & CHEMICAL STRUCTURE & CHEMICAL NAME & ACTIVITY & REF \\
\hline 1. & Anticancer \\
and Cytostatic
\end{tabular}


Quinoxaline as a potent heterocyclic...

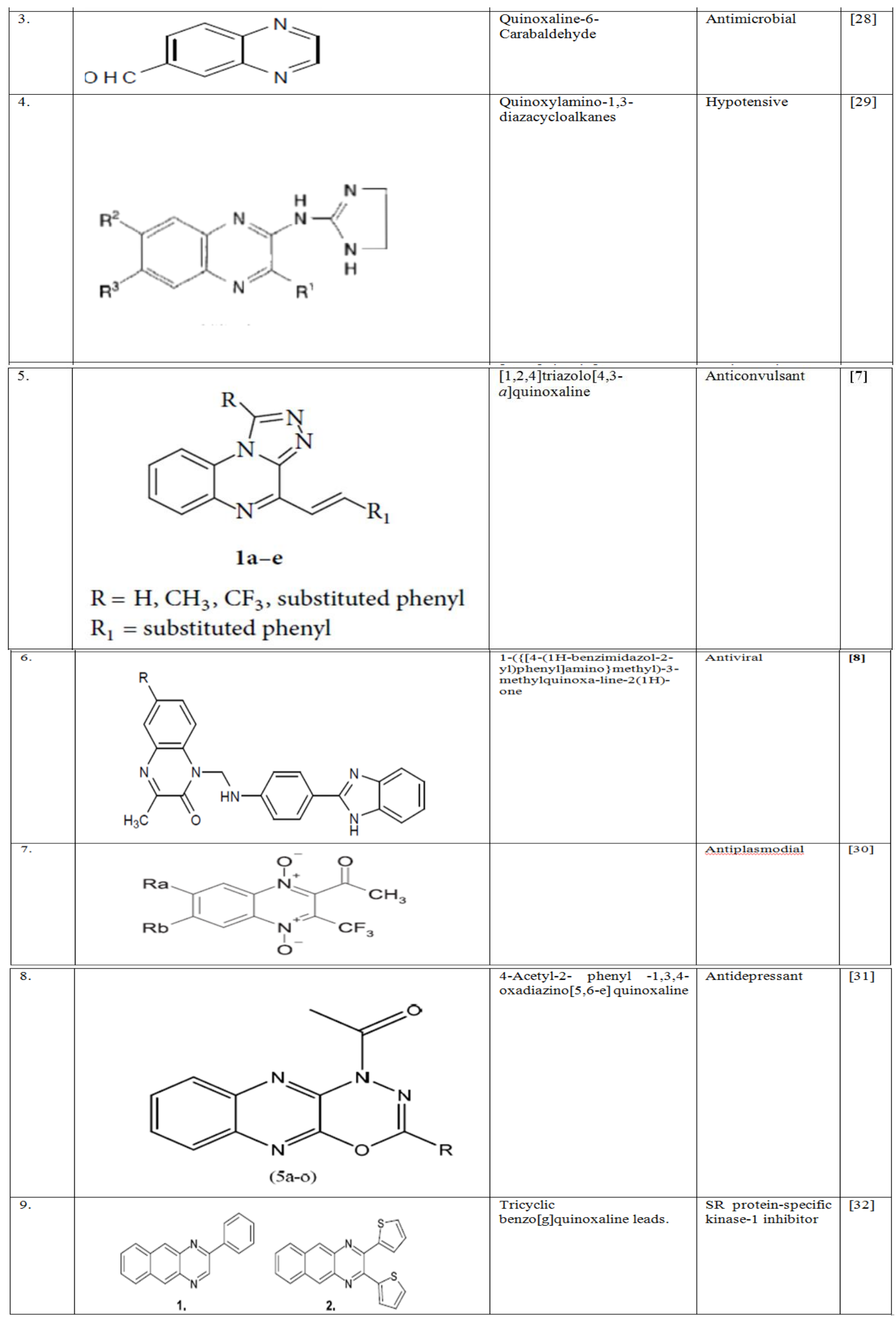




\section{CONCLUSION}

This review gives an overview of the various synthetic routes used to form a biologically rich quinoxaline moiety.This paper proves to be helpful for further research work on the bioactive quinoxaline ring and as an important tool for the development of better medicinal agents and newer compounds possessing quinoxaline moiety that could be better agents in terms of efficacy and safety.

\section{REFERENCE:}

[1]. Noorulla Smd, Sreenivasulu N, Khan A And Sayeed A Antibacterial Activity Of Novel Substituted Quinoxaline Heterocycles ISSN 0976 -3090 (Print), 2231- 0541 (Online) Pharmanest Pharmanest - An International Journal of Advances In Pharmaceutical Sciences Vol.2 (2 - 3) March - June -2011 www.pharmanest.net

[2]. KarkiS. S. , Hazare R, Vivek K. S. Bhadauria S , Balzarini J,Clercq D, Synthesis, anticancer and cytostatic activity of some 6H-indolo[2,3-b]quinoxalinesActa Pharm. 59 (2009) 431-440 Original research paper 10.2478/v10007-009-0040-9)

[3]. Singh, D. P ; Hashim, Syed R and Singhal, R G, Anti Inflammatory Activity Of Some New Thio-Ether Derivatives Of Quinoxaline International Journal of Drug Development \& Research Oct-Dec 2010 | Vol. 2 | Issue 4 | ISSN 0975-9344

[4]. Antonio C, Giuseppe P, Mohammad E. R, Nikookar a,Paolo S, Leonardo S, Stefania Z, Novel substituted quinoxaline 1,4-dioxides with in vitro antimycobacterial and anticandida activity ( Eur. J. Med. Chem. 37 (2002) 355-366Original article

[5]. . . Rong S, Yu X, Qinjie W, Qing X, Qiaojun H, Bo Y, Yongzhou H, Synthesis and cytotoxic activity of 3-phenyl-2-thio-quinoxaline1,4-dioxide derivatives in hypoxia and in normoxia Original Article http://www.ddtjournal.com Drug Discov Ther 2007;1(2):119-123. Original Article

[6]. Hossain MM, Hossain MM, Muhib MH, Mia MR, Kumar S, Wadud SA, In Vitro Antioxidant Potential Study Of Some Synthetic Quinoxalines Bangladesh Med Res Counc Bull 2012; 38: 47-50,

[7]. Alswah M, Ghiaty A, El-Morsy A, and El-Gamal K, Synthesis and Biological Evaluation of Some $[1,2,4]$ Triazolo[4,3-a]quinoxaline Derivatives as NovelAnticonvulsant Agents Hindawi Publishing Corporation ISRN Organic Chemistry Volume 2013, Article ID 587054, 7 page http://dx.doi.org/10.1155/2013/587054Research Article

[8]. Mahmoud A. A, Mohamed M. Y,Use of Modern Technique for Synthesis of Quinoxaline Derivatives as Potential Anti-Virus Compounds Der Pharma Chemica, 2012, 4 (3):13231329(http://derpharmachemica.com/archive.html)ISSN 0975-413XCODEN (USA): PCHHAX

[9]. Zsolt Sze kelyhidi,a Ja'nos Pato' ,b Frigyes Wa'czek,a Pe'ter Ba'nhegyi,a Ba'lint HegymegiBarakonyi,a Dániel Er\}os,b Gyo"rgy Me'sza'ros,a Ferenc Hollo' sy,aDoris Hafenbradl,d Sabine Obert,d Bert Klebl,d Gyo 'rgy Ke'ria,b,* and La'szlo' \}Orfia,b,c Synthesis of selective SRPK-1 inhibitors:Novel tricyclic quinoxaline derivatives Received 21 March 2005; accepted 28 April 2005 Available online 31 May 2005

[10]. Patidar A. K, Jeyakandan M., Mobiya A. K, Selvam G. International Journal of PharmTech ResearchCODEN (USA): IJPRIF ISSN : 0974-4304 Vol. 3, No.1, pp 386-392, Jan-Mar 2011Exploring Potential of Quinoxaline Moiety

[11]. Atghia S. V and Beigbaghlou S. S, Nanocrystalline titania-based sulfonic acid(TiO2-Pr-SO3H) as a new, highly efficient,and recyclable solid acid catalyst for preparation of quinoxaline derivatives Atghia and Beigbaghlou Journal Of Nanostructure inChemistry 2013, 3:38 http://www.jnanochem.com/content/3/1/38

[12]. Sajjadifar S, Noorizadeh H, Veisi H, Louie O, Avval M. M, Rezayati S, A Facile and Efficient Method for the Synthesis of Quinoxaline Derivatives Using [(Sulfooxy)Ethyl]Sulfamic Acid as a Novel Difunctional Bronsted Acid, Recyclable and Organocatalyst Research Journal of Pharmaceutical, Biological and Chemical Sciences ISSN: 0975-8585 October-December 2013 RJPBCS Volume 4 Issue 4 Page No. 906

[13]. Karami B. And Khodabakhshi S, A facile synthesis of phenazine and quinoxaline derivativesusing magnesium sulfate heptahydrate as a catalyst (Received 1 August, revised 29 November 2010) J. Serb. Chem. Soc. 76 (9) 25-1198 (2011) JSCS-4194 Original scientific paper

[14]. Heravi M. M., Bakhtiari K, Tehrani M.H, Javadi N. M, and Oskooie H, A Facile synthesis of quinoxaline derivatives using o-iodoxybenzoic acid (IBX) at room temperature General Papers ARKIVOC 2006 (xvi) 16-22 ISSN 1424-6376 
[15]. Li-Yan Fan, Lin Wei, Wen-Jun Hua, Xiang-Xiong Li Yb modified NaY zeolite: A recyclable and efficient catalyst for quinoxaline synthesisChinese Chemical Letters 25 (2014) 1203-1206Received 23 December 2013 Received in revised form 20 February 2014 Accepted 21 February 2014 Available online 12 March 2014

[16]. Nagarapu. L, Palem J D, Reddy R. K, Bantu A and R, A Facile and Efficient Synthesis of Quinoxalines from Phenacyl Bromides and Ortho Phenylenediamine Promoted by Zirconium TungstatenBaranwal et al. Organic Chem Current Res 2014, S4 http://dx.doi.org/10.4172/2161-0401.S4-001

[17]. Soleymani R, Niakan N, Tayeb S And Hakimi S. Synthesis of Novel Aryl Quinoxaline Derivatives by New Catalytic Methods ORIENTAL JOURNAL OF CHEMISTRY www.orientjchem.org Est. 1984 An International Open Free Access, Peer Reviewed Research Journal ISSN: 0970-020 X CODEN: OJCHEG 2012, Vol. 28, No. (1):Pg. 687-701

[18]. Sajjadifar S, Mohammad A. Z, Gholamabbas C,Sara M, Parvin M, Qinoxaline II. A Practical Efficient And Rapid Synthesis Of New Quinoxalines Catalyzed By Citric Acid As Trifunctional Bronsted Acid At Room Temperature Under Green Condition International Journal of ChemTech Research CODEN( USA): IJCRGG ISSN : 0974-4290Vol.5, No.1, pp 422-429, Jan-Mar 2013

[19]. Biswas S and Batra S, Copper-catalysed synthesis of substituted isoindolo[2,1-a]quinoxalines and isoindolo[2,1-a]quinoxalin-6(5H)-ones§European Journal Organic Chemistry. 2013, 4895-4902

[20]. Ren-xin SHI, Yun-kui LIU†, Zhen-yuan XU Sodium tetrachloroaurate(III) dihydrate-catalyzed efficient synthesis of 1,5-benzodiazepine and quinoxaline derivatives*Journal of Zhejiang UniversitySCIENCE B (Biomedicine \& Biotechnology) ISSN 1673-1581 (Print); ISSN 1862-1783 (Online) www.zju.edu.cn/jzus; www.springerlink.comE-mail: jzus@zju.edu.cnShi et al. 102 / J Zhejiang UnivSci B (Biomed \& Biotechnol) 2010 11(2):102-108

[21]. JI Yun-fei, CHEN Tang-ming, MAO Hai-feng and ZOU Jian-ping Ga(ClO4)3-catalyzed Reaction of 1,2-Diamines and $\alpha$-Bromoketones: Synthesis of 2-Substituted Quinoxalines CHEM. RES. CHINESE UNIVERSITIES 2012, 28(4), 642-646

[22]. Tai Kun, Lin Shi, Rui Wang, Xing Zhou Guo, Xiao Xia Lu Keggin type heteropolyacids-catalyzed synthesis of quinoxaline derivatives in water Chinese Chemical Letters 20 (2009) 161-164* Corresponding author. E-mail address: xlua71@ yahoo.com.cn (X.X. Lu)

[23]. Cartigny D, Nagano T, Ayad T, GenTt J, Ohshima T, Mashima K and Vidala V R, IridiumDifluorphos-Catalyzed Asymmetric Hydrogenation of 2-Alkyl- and 2-Aryl-Substituted Quinoxalines: A General and Efficient Route into Tetrahydroquinoxalines _ 2010 Wiley-VCH Verlag GmbH\&Co. KGaA, Weinheim Adv. Synth. Catal. 2010, 352, 1886 - 1891Received: June 30, 2010; Published online: August 16, 2010

[24]. Pawara O. B., Chavanb F. R., Suryawanshia V. S., Shindea V. S. And Shindea N. D, Thiamine hydrochloride: An efficient catalyst for one-pot synthesis of quinoxaline derivatives at ambient temperature.

[25]. Heravi M. M., Bakhtiari K, Tehrani M. H., Javadi N. M., and Oskooie H, A. Facile synthesis of quinoxaline derivatives using o-iodoxybenzoicacid (IBX) at room temperature General Papers ARKIVOC 2006 (xvi) 16-22

[26]. Bandyopadhyay D, Mukherjee S, Rodriguez R. R. and Banik B. K. An Effective Microwave-Induced Iodine-Catalyzed Method for the Synthesis of Quinoxalines via Condensation of 1,2-Diamines with 1,2-Dicarbonyl CompoundsMolecules 2010, 15, 4207-4212; doi:10.3390/molecules15064207 ISSN 1420-3049 www.mdpi.com/journal/molecules

[27]. Das J, Sarkar S, An Efficient Synthesis Of Quinoxalines In Water Mediated By tetraethylammonium Bromatepranab Received: September 02, 2011; Accepted: October 07, 2011 International Journal of Chemical Research ISSN: 0975-3699 \& E-ISSN: 0975-9131, Vol. 3, Issue 2, 2011, pp-56-60

[28]. Pai N. R., Vishwasrao S. G. A novel synthesis of quinoxaline- 6-carabaldehyde and its evaluation as potential antimicrobial agent Der Pharma Chemica, 2011, 3 (6):591-598 ISSN 0975-413XCODEN (USA): PCHHAX

[29]. Foks H, Wisterowicz K, Nasal A, Damasiewicz B And Radwanska A, Studies On Quinoxaline Derivatives , Synthesis Of Quinoxalkylamino 1,3-Diazocycloalkanes With Potntial Hypotensive Activity.Drug Research Vol 56 No 3 Pp201-206,1999 Issn001 6837

[30]. Zarranz. B, Jaso A, Lima L. M, Aldana I, Monge A, Maurel S and Sauvain M,Antiplasmodial activity of 3-trifluoromethyl-2-carbonylquinoxaline di-N-oxide derivativesRevista Brasileira de Ciências Farmacêuticas Brazilian Journal of Pharmaceutical Sciences vol. 42, n. 3, jul./set., 2006 
[31]. Suryawanshi M. R., Kulkarni V. M., Mahadik K. R., Bhosale S. H, Synthesis, Pharmacological Evaluation and QSAR Study of 2-aryl-1H-[1, 3,4] oxadiazino [5, 6-b] quinoxalines as Antidepressants Archives of Applied Science Research, 2011, 3 (1): 380-391ISSN 0975-508X CODEN (USA) AASRC9

[32]. Zsolt Sze kelyhidi,a János Pato' ,b Frigyes Wa'czek,a Péter Bánhegyi,aBa'lint HegymegiBarakonyi,a Da'niel Er\}os,b Gyo"rgy Me'sza'ros,a Ferenc Hollo' sy,aDoris Hafenbradl,d Sabine Obert,d Bert Klebl,d Gyo“rgy Ke'ria,b,* and La'szlo'\}Orfia,b,c Synthesis of selective SRPK-1 inhibitors:Novel tricyclic quinoxaline derivative Received 21 March 2005; accepted 28 April 2005 Available online 31 May 2005 